\title{
A comparison of daily representations of canopy conductance based on two conditional time- averaging methods and the dependence of daily conductance on environmental factors
}

\author{
Nathan Phillips, Ram Oren*
}

Nicholas School of the Environment, Duke University, Durham, NC 27708-0328, USA

(Received 15 January 1997; accepted 23 September 1997)

\begin{abstract}
In hydrological models which incorporate vegetated surfaces, non-steady state responses in stem sap flow to diurnal evaporative demand can lead to unreasonable values of computed canopy conductance, which corrupt diurnal courses and daily averages. Conductance computations based on daily averaged constituent variables are a potential method for circumventing this problem. However, comparisons between these two averaging methods are lacking. In this study, both methods for computing daily canopy conductance were compared in a pine forest. A simplification of the Penman-Monteith equation under conditions of high aerodynamic coupling was used to calculate instantaneous canopy conductance. Large variation between the two methods was observed due to biases introduced under conditions of low sap flow or vapor pressure deficit. Two conditional averaging schemes were developed to exclude data which were strongly affected by such conditions, and as a result of the conditional averaging, a tighter relationship between these two averaging schemes was found. We calculated daily representations of canopy conductance for an entire growing season in a 15-year-old Pinus taeda stand. Despite clear declines in conductance between rain events in direct response to soil water depletion, and large seasonal dynamics in canopy leaf area, canopy conductance remained generally uniform until low late season temperatures. (@ Inra/Elsevier, Paris.)
\end{abstract}

Pinus taeda / canopy conductance / sap flux / soil water balance

Résumé - Comparaison des estimations de conductance de couvert journalière basées sur deux méthodes de moyennes temporelles conditionnelles, et effet des facteurs de l'environnement. Dans les modèles hydrologiques qui prennent en compte les surfaces végétales, les estimations de la conductance du couvert pour la vapeur d'eau faites à partir des mesures de flux de sève et de la demande climatique peuvent conduire à des valeurs instantanées et des

\footnotetext{
* Correspondence and reprints

Tel: (1) 919613 8032; fax: (1) 919684 8741; e-mail: ramoren@duke.edu
} 
moyennes journalières erronées, à cause d'un régime de flux hydrique non conservatif. Un calcul de la conductance basé sur les moyennes journalières de certaines variables est une méthode pour résoudre ce problème. Toutefois, la comparaison entre les deux méthodes n'avait pas encore été effectuée. Ce travail compare ces deux méthodes de calcul de la conductance de couvert pour une forêt de pins. L'équation de Penman-Monteith a été simplifiée, en supposant un fort couplage entre le couvert et l'atmosphère, et utilisée ici pour calculer les valeurs instantanées de conductance de couvert. Un écart important entre les deux méthodes a été mis en évidence, à cause des biais apparaissant en conditions de flux de sève ou de déficit de saturation de l'air faibles. Deux procédures de moyennage conditionnel ont été développées pour exclure ce type de données, et une relation étroite entre les deux méthodes a été trouvée. La conductance de couvert journalière a été ainsi calculée sur une saison de végétation complète dans un peuplement de Pinus taeda âgé de 15 ans. En dépit de la diminution de conductance entre les épisodes de pluie, conduisant à des déficits hydriques dans le sol, et de variations importantes d'indice foliaire au cours de la saison, la conductance du couvert est restée uniforme jusqu' aux basses températures de la fin de la saison. (@ Inra/Elsevier, Paris.)

Pinus taeda / conductance de couvert / flux de sève / bilan hydrique

\section{INTRODUCTION}

The development of proper methods for averaging canopy stomatal conductance, both spatially and temporally, remains a subject of active research. In temporal representations of canopy conductance, the daily time scale is particularly important. Many climate or hydrological models that involve canopy conductance use or predict information on this time scale (e.g. $[3,6,39,45,47]$ ); moreover, many climatological data are available only at the daily scale [47]. However, an appropriate daily representation of canopy conductance lacks consensus (e.g compare the approaches in Tattori et al. [41]; Couralt et al. [6]; Fennessey and Vogel [7]; Kustas et al. [23]), in spite of improvements in the ability to obtain conductance information diurnally $[13,30]$. Extrapolation from maximum diurnal values of leaf or canopy conductance to averaged daily conductance estimates based on environmental relationships [16] has yielded reasonable results (e.g. [34, 35]), but this approach depends on steady state relationships between conductance and environmental variables, which may not be applicable within diurnal time scales
$[15,46]$. Other modeling approaches have used midday conductance information (e.g. [39]) or fixed values (see Shuttleworth [37]) as representative of daily conductance. However, it is necessary to examine how well such values generalize diurnal patterns of conductance. In this study we evaluate differences in conductance values calculated based on mean daily conditions versus those based on averages of diurnal values.

The use of stem sapflow measurements in conjunction with meteorological measurements of evaporative demand has provided a method in which continuous estimates of canopy conductance may be made $[12,13]$. The advent of this technology has alleviated the constraint of extrapolating conductances over time based on steady state environmental relationships, or using single points within a day as representative of daily conductance. However, the ability to continuously measure stem flux and environmental driving forces for use in conductance calculations has presented a new challenge: resolving diurnal non-steady state canopy and stem characteristics and their effects on calculations of instantaneous and daily average conductance. 
Leaf and canopy conductances have been demonstrated to exhibit time lags with respect to changes in environmental influences [46]. Furthermore, due to effects of hydraulic capacitance and resistance, sap fluxes measured in stems of trees lag behind canopy transpiration [13, $32,36]$. Unless the time constants for these processes can be determined precisely and generally over a range of environmental conditions (e.g. water stress) the combined presence of both of these effects may lead to errors in instantaneous computations of canopy conductance. Such instantaneous errors may then be propagated to daily estimates.

An alternative method for estimating daily conductance which potentially avoids the problems presented by averaging instantaneous diurnal values is a calculation based on daily averages of the constituent variables. In principle, the total daily transpiration could be related to the total daily driving force, without the complications arising from improper diurnal matching of the two. The objective of this study was to investigate how such a method for calculation of average daily canopy conductance (hereafter referred to as 'daily' conductance, or $\boldsymbol{G}_{\mathrm{C}, \text { day }}$ ) differed from one which used daily averages of diurnal values of conductance (hereafter referred to as 'mean diurnal' conductance, or $\boldsymbol{G}_{\mathrm{C}, \mathrm{diu}}$ ).

The specific questions addressed by this study were: if an inverse form of the Penman-Monteith equation is used to calculate conductance, how will averaged daily thermodynamic variables, based on average daily temperature, differ from those obtained as the average of diurnal, temperature-dependent measurements? How will nighttime uptake of water (either from normal recharge or rain recharge) differentially affect results of the two averaging techniques? Will the difference between a daily and diurnal conductance be a function of tree size or absolute daily flux rates? Having addressed these questions, the proposed study suggests a general, robust computational and conditional averaging scheme for generating daily canopy conductances in experiments where diurnal conductance values are available. Further, the dependence of such a daily canopy conductance on environmental factors such as rain and soil moisture depletion is investigated.

\section{MATERIALS AND METHODS}

The study was conducted in Duke Forest, North Carolina, USA, in a managed, 15-yearold Loblolly pine stand. More details on the site are given in Phillips et al. [31]. Leaf area index $(\boldsymbol{L})$, derived from allometric relationships between leaf area and sapwood area, coupled with a foliage dynamics model [18], ranged from 2.01 to 3.27 during this period. Measurements needed to compute canopy conductance for 20 individuals were initiated on 4 April 1995, and continued until 28 December 1995. All measurements were made at $30-\mathrm{s}$ intervals and averaged and recorded every 30 min with a data logger (Delta-T Devices, UK).

Sap flow $\left(\mathrm{g}_{\mathrm{H}_{2} 0} \mathrm{~m}_{\mathrm{xylem}}^{-2} \mathrm{~s}^{-1}\right)$ was estimated with constant-heat probes as described in Granier $[11,12]$. Sap flux densities of individual trees were scaled to the plot level by multiplying average sap flux densities by the amount of xylem area per unit ground area in the stand, corrected for a reduced flux rate found in inner xylem [29].

Air temperature and relative humidity were measured at the bottom of the upper third of the forest canopy with a Vaisala HMP 35C temperature and humidity probe (Vaisala, Helsinki, Finland). Air vapor pressure deficit $(\boldsymbol{D})$ was calculated from air temperature and relative humidity according to Goff and Gratch [10]. Photosynthetically active radiation (PAR) was measured above the canopy with a spherical quantum sensor (LI-193SA, Licor, Inc., Lincoln, Nebraska, USA). Rainfall was measured to the nearest $0.1 \mathrm{~mm}$ in a forest clearing ca $100 \mathrm{~m}$ away from the site with a Texas Electronics Tipping Bucket Rain Gage (Texas Electronics, Dallas, Texas, USA). However, midway through the season, this instrument failed. Therefore, subsequent rain data were obtained 
from a National Weather Service station located ca $5 \mathrm{~km}$ from the site.

\subsection{Diurnal versus daily conductance calculations}

All conductances were calculated according to Monteith and Unsworth [26] as

$$
\boldsymbol{G}_{\mathrm{C}}=\frac{\gamma(\mathrm{T}) \cdot \lambda(\mathrm{T}) \cdot \boldsymbol{E}_{\mathrm{C}}}{\mathrm{C}_{\mathrm{p}} \cdot \rho(\mathrm{T}) \cdot \boldsymbol{D}}
$$

where $\gamma$ is the psychrometric constant, $\lambda$ is the latent heat of vaporization of water, $C_{p}$ is the specific heat of air, $\rho$ is the density of liquid water, $\mathrm{T}$ is temperature, $\boldsymbol{E}_{\mathrm{C}}$ is evaporation rate, and $\boldsymbol{D}$ is vapor pressure deficit of the canopy air. This simplification of the Penman-Monteith equation is based on the assumption that the pine forest was well coupled aerodynamically [17]; thus $D$ approximated the total driving force for transpiration. We checked the assumption of strong coupling in this forest by selecting a six-d period from 23-28 May 1995 for diurnal comparisons of aerodynamic conductance $\left(\boldsymbol{G}_{\mathrm{A}}\right)$ with total canopy conductance $\left(G_{C}\right)$. Aerodynamic conductance was computed according to Thom and Oliver [43] as

$$
\boldsymbol{G}_{\mathrm{A}}=\frac{0.212(1+0.54 \boldsymbol{U})}{\left[\ln \left((z-\boldsymbol{d}) / z_{0}\right)\right]^{2}}
$$

where $\boldsymbol{U}$ is windspeed $\left(\mathrm{m} \mathrm{s}^{-1}\right)$ at height $z(11.5$ $\mathrm{m}), z_{0}$ is roughness length (set as $1 / 10$ of canopy height, or $1 \mathrm{~m}$ ), $\boldsymbol{d}$ is zero plane displacement (taken as $2 / 3$ of canopy height, or 6.7 $\mathrm{m})$. Over the 6-d period, $G_{\mathrm{C}}$ computed according to equation (1) averaged $4.5 \mathrm{~mm} \mathrm{~s}^{-1}$ ( $\mathrm{SE}=$ $0.2 \mathrm{~mm} \mathrm{~s}^{-1}$ ), only $2.4 \%$ of $\boldsymbol{G}_{\mathrm{A}}$, which averaged $187 \mathrm{~mm} \mathrm{~s}^{-1}\left(\mathrm{SE}=1 \mathrm{~mm} \mathrm{~s}^{-1}\right)$. At one point within the 6-d period, $G_{\mathrm{C}}$ reached, at maximum, $10.9 \%$ of $G_{\mathrm{A}}$. Thus, the assumption that $\boldsymbol{G}_{\mathrm{C}} \gg \boldsymbol{G}_{\mathrm{A}}$ made in equation (1) appeared to be satisfied.

The different averaging procedures for equation (1) compared in this study are summarized in table $I$ and are discussed in further detail in the following sections.

\subsection{Diurnal calculation of canopy conductance, $G_{\mathrm{C} \text {,diu }}$}

Equation (1) was solved at every 30-m step, using $\boldsymbol{E}_{\mathrm{C}}, \boldsymbol{D}$ and temperature at that time to calculate the appropriate thermodynamic constants. Data were averaged over the period each

\begin{tabular}{|c|c|c|c|}
\hline Averaging approach & Corresp & onding calculation & Ised \\
\hline \multirow{2}{*}{ Diurnal } & \multirow{2}{*}{$\boldsymbol{G}_{\mathrm{Cdiu}}=$} & $\lambda(\mathrm{T}(\mathrm{t})) \cdot \gamma(\mathrm{T}(\mathrm{t}))$ & $\boldsymbol{E}_{\mathrm{C}}(\mathrm{t})$ \\
\hline & & $\rho(\mathrm{T}(\mathrm{t})) \cdot \mathrm{C}_{\mathrm{p}}$ & $D(\mathrm{t})$ \\
\hline \multirow{2}{*}{ Daily (means of diurnal $\lambda, \gamma, \rho$ ) } & \multirow{2}{*}{$\boldsymbol{G}_{\mathrm{C}, \mathrm{day}}^{\prime}=$} & $=\lambda(\mathrm{T}(\mathrm{t})) \cdot \gamma(\mathrm{T}(\mathrm{t}))$ & $\overline{E_{\mathrm{C}}(\mathrm{t})}$ \\
\hline & & $\rho(\mathbf{T}(\mathrm{t})) \cdot \mathrm{C}_{\mathrm{p}}$ & $\overline{D(t)}$ \\
\hline \multirow{2}{*}{ Daily $(\lambda, \gamma, \rho$ from mean daily $\mathrm{T})$} & \multirow{2}{*}{$\boldsymbol{G}_{\mathrm{C}, \mathrm{day}}=$} & $\lambda \overline{(\mathrm{T}(\mathrm{t}))} \cdot \gamma \overline{(\mathrm{T}(\mathrm{t}))}$ & $\overline{E_{\mathrm{C}}(\mathrm{t})}$ \\
\hline & & $\rho \overline{(\mathrm{T}(\mathbf{t}))} \cdot \mathrm{C}_{\mathrm{p}}$ & $\overline{D(\mathrm{t})}$ \\
\hline
\end{tabular}

Table I. Comparison of 'diurnal' and 'daily' averaging procedures compared in this study.

The 'daily' averaging scheme required further inspection of effects of temperature on daily averages of thermodynamic variables. Variables are defined in the text. 
day when PAR $>0 \mu \mathrm{mol} \mathrm{m} \mathrm{m}^{-2} \mathrm{~s}^{-1}$ (hereafter referred to as daylight hours).

\subsection{Daily calculation of canopy conductance, $G_{\mathrm{C}, \text { day }}$}

Equation (1) was solved using averages of all quantities over the day. Values of the thermodynamic variables were based on the average temperature over daylight hours. Daily vapor pressure deficit $\left(\boldsymbol{D}_{\mathrm{D}}\right)$ was also obtained by averaging $\boldsymbol{D}$ over daylight hours, under the assumption that this is the time period in which $D$ has an effect on transpiration and, therefore, uptake. Transpiration $\left(\boldsymbol{E}_{\mathrm{C}}\right)$, however, was summed over $24 \mathrm{~h}$ but divided by daylight hours only, because: 1 ), this accounted for all water uptake driven by $\boldsymbol{D}$ over the day; and 2) it provided a consistent averaging period with that used for $D_{\mathrm{D}}$. Starting and ending points for days were taken as from 0500 to 0500 hours (steady state conditions), after concluding that using a 0000 to 0000 hours integration period may be subject to large relative errors. These errors are introduced under conditions of low absolute daily transpiration (figure I).

\subsection{Comparison of daily versus diurnal conductance values}

A direct comparison between diurnal and daily averaged conductance was made to indicate the most general differences between the two methods over all conditions of $\boldsymbol{E}_{\mathrm{C}}$ and $\boldsymbol{D}$. In order to assess the influence of extremely low $D$ values and their possible cause of extremely high apparent conductance values, a conditional averaging scheme (hereafter referred to as the diurnal conditional average) was applied to the diurnal values so as to exclude all $D$ values $<0.1 \mathrm{kPa}$. The $0.1-\mathrm{kPa}$ cutoff was selected after observing unreasonably high and low conductance values obtained for $D<0.1 \mathrm{kPa}$. (the reasons for which will be stated in the results section). This conditional average (denoted by brackets) can be expressed in symbols as

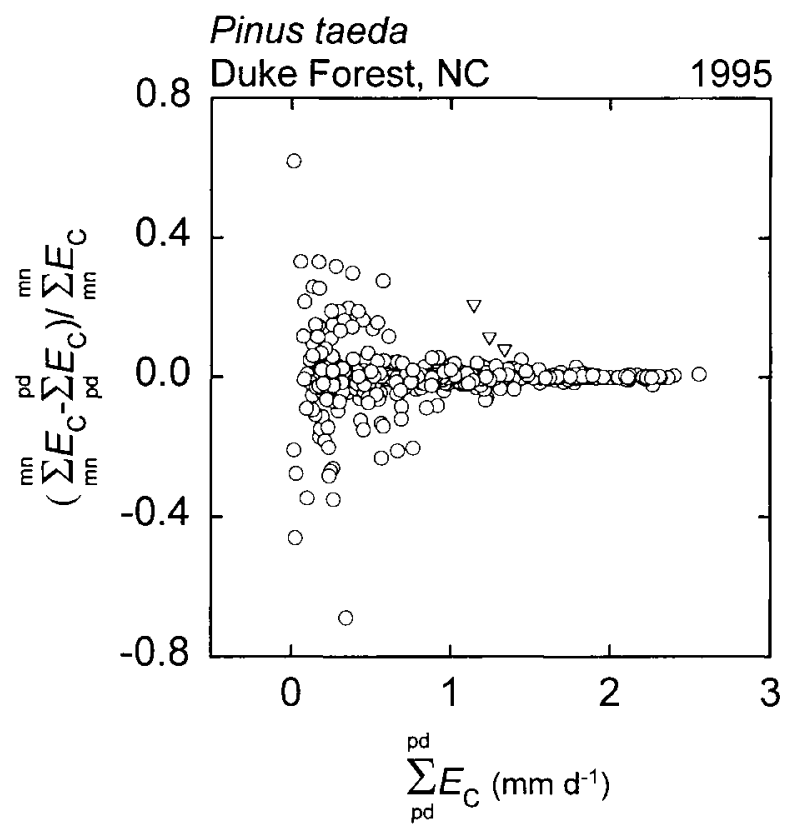

Figure 1. Relative difference in daily stand water flux $\left(\Sigma \boldsymbol{E}_{\mathrm{C}}\right)$ when time taken as the start of day was 0500 hours (labeled pd for predawn) versus 0000 hours (labeled $\mathrm{mn}$ for midnight). Open triangles represent days for which nighttime recharge due to an evening rain event occurred. 


$$
\begin{aligned}
& \boldsymbol{G}_{\mathrm{C} ; \mathrm{diu}}=\frac{\gamma \lambda}{\boldsymbol{C}_{\mathrm{p} \rho}}<\boldsymbol{E}_{\mathrm{C}} / \boldsymbol{D}> \\
& \left.<\boldsymbol{E}_{\mathrm{C}} / \boldsymbol{D}\right\rangle=\mid \frac{\mathbf{l}}{\mathrm{n}} \cdot \sum_{\mathrm{i}=1}^{\mathrm{N}}\left(\boldsymbol{E}_{\mathrm{C}} / \boldsymbol{D}\right)_{\mathrm{i}} \cdot \mathrm{I}_{\mathrm{i}}
\end{aligned}
$$

where

$$
I_{i}=\mid \begin{gathered}
I \text { if } \boldsymbol{D}>0.1 \mathrm{kPa} \text { and } \mathrm{PAR}>0 \\
0 \text { otherwise }
\end{gathered}, \mathrm{n}=\sum_{\mathrm{i}=1}^{\mathrm{N}} \mathrm{I}_{\mathrm{i}}
$$

and $\mathrm{N}$ is the number of diurnal observations. The number of points, $n$, for each daytime period in which $\mathbf{I}_{\mathrm{i}}=1$ was recorded to assess the effect of sample size on the calculation of daily conductance values. A secondary condition was applied to exclude days for which $n$ was too small to provide reasonable statistical representation of the daytime conductance (hereafter referred to as the daily conditional average). The choice of this $\mathrm{n}$ will be discussed in the results section.

\section{RESULTS}

\subsection{The potential of cross-correlation analysis to rectify non-steady state behavior}

Cross-correlation analysis over the whole data set showed no difference in $\mathrm{r}$
$(=0.85)$ between a $0-$ and a $60-$ min lag for $\boldsymbol{D} \times \boldsymbol{E}_{\mathrm{C}}$. Thus we could not justify applying a constant time lag to the entire data set to correct for non-steady state behavior. Conductance calculations were therefore based on $\boldsymbol{D}$ and $\boldsymbol{E}_{\mathrm{C}}$ with zero lag.

\subsection{Comparison of daily versus diurnal thermodynamic constants}

The approximation of temperaturedependent thermodynamic variables as constants (e.g. as defined at standard temperature) in calculations of conductance can lead to significant errors if significant temperature variation occurs. We calculated a $12 \%$ relative difference in a combined conductance coefficient (table II) between 0 and $35{ }^{\circ} \mathrm{C}$ due to temperature dependence of the conductance coefficient. Thus, including temperature dependence into the thermodynamic variables involved in the conductance calculation is necessary under conditions of significant temperature variability. For the purpose of calculating daily average canopy conductance, this temperature dependence leads to a question as to whether the thermodynamic constants can be averaged from diurnal values, or calculated from average daily temperature, before being

Table II. Regression of thermodynamic variables on air temperature, $\mathrm{T}\left({ }^{\circ} \mathrm{C}\right)$ and resulting conductance coefficient $\left(\mathrm{K}_{\mathrm{g}}\right)$.

\begin{tabular}{llcccc}
\hline Quantity & \multicolumn{1}{c}{ Description } & Units & Intercept & Slope & $\mathrm{r}^{2}$ \\
\hline$\rho$ & density of air & $\mathrm{kg} \mathrm{m}^{-3}$ & 1.283 & $4.48 \mathrm{e}-3$ & 0.994 \\
$\lambda$ & latent heat of vaporization & $\mathrm{J} \mathrm{kg}^{-1}$ & $2.502 \mathrm{e} 6$ & $-2.308 \mathrm{e} 3$ & 0.998 \\
$\mathrm{C}_{\mathrm{p}}$ & specific heat of air at constant pressure & $\mathrm{J} \mathrm{kg}^{-1} \mathrm{~K}^{-1}$ & $1.010 \mathrm{e} 3$ & - & 1.000 \\
$\gamma$ & psychrometric constant & $\mathrm{kPa} \mathrm{K}^{-1}$ & $6.49 \mathrm{e}-2$ & $6.071 \mathrm{e}-5$ & 0.999 \\
$\mathrm{~K}_{\mathrm{g}}$ & c onductance coefficient $\left(\lambda \gamma \rho^{-1} \mathrm{C}_{\mathrm{p}}^{-1}\right)$ & $\mathrm{kPa} \mathrm{m}^{3} \mathrm{~kg}^{-1}$ & $1.158 \mathrm{e} 2$ & $4.236 \mathrm{e}-1$ & 0.999 \\
\hline
\end{tabular}

The ratio of stand water flux to vapor pressure deficit, $\boldsymbol{E}_{\mathrm{C}} \boldsymbol{D}^{-1}$, is expressed in $\mathrm{kg} \mathrm{m}^{-2} \mathrm{~s}^{-1} \mathrm{kPa}^{-1}$. Values obtained from Oke (1995) for the air temperature range -30 to $+45^{\circ} \mathrm{C}$. Regressions used in this study were for the range -5 to $+35^{\circ} \mathrm{C}\left(\mathrm{K}_{\mathrm{g}}=115.8+0.4226 \mathrm{~T} ; \mathrm{r}^{2}=0.999\right)$. 
used in equation (1). The answer to this question depends upon whether the temperature dependence of the thermodynamic variables can be approximated as linear over the appropriate temperature range. Relationships between $\gamma, \lambda$ and $\rho$ with temperature $\left(C_{p}\right.$ has very weak temperature dependence [28]) are highly linear over the temperature range of physiological importance (defined for this study as the range -5 to $35^{\circ} \mathrm{C}$; table $I I$ ). Thus, we conclude that a combined conductance coefficient can be used as a function of mean daytime temperature, for the purpose of calculating average daily conductance according to equation (1).

\subsection{Pre-conditionally averaged comparison between diurnal and daily conductance}

Very large errors in computed diurnal conductance can result from conditions in which transpiration and/or vapor pressure deficit have very low values [2]. In addition to lags between sap flux and vapor pressure deficit leading to magnified errors at low absolute values of vapor pressure deficit, slight biases in measurements of either vapor pressure deficit or sap flow may lead to diverging conductance values when approaching a zero/zero ratio (specified error $= \pm 3 \%$ in relative humidity at $>90 \%$ for the HMP35C transducer we used; also, sap flux measurements may exhibit a small bias at low absolute values as a result of violation of assumptions of zero flux at night [12]). Indeed, such potential sources of error add to the motivation for using daily averaged constituent variables in a daily conductance calculation.

We found that such unreasonably high or low apparent instantaneous conductances, obtained under conditions where $\boldsymbol{D}<0.1 \mathrm{kPa}$, were influential enough to lead to unreasonably high or low daily averaged conductance, both when this conductance was obtained by averaging diurnal values (over light hours) or when using the averaged constituent variables in a daily scale calculation (figure $2 a$ ). In addition, the difference between daily conductance based on diurnal values and that based on daily averages showed a large divergence at low $\boldsymbol{D}_{\mathrm{D}}$ (figure $2 b$ ).

\subsection{Effect of diurnal conditional averaging of conductance values on the comparison between diurnal and daily conductance}

After examination of portions of our data set in which low diurnal vapor pressure deficit values occurred, both on mornings and evenings of clear days and throughout overcast diurnals (e.g. figure 3) a combination conditional average based on light level and a minimum $\boldsymbol{D}$ was defined. Conductance values in which $\mathrm{I}_{\mathrm{i}}$ $=0$ were excluded from averaging over the diurnal time series. The included and excluded data as a result of this conditional averaging are illustrated in figure 3 for two typical diurnal time series. The result of this averaging scheme on the relationship between computed daily and average diurnal conductances is demonstrated in figure $2 c, d$. The conditional averaging led to a much reduced range of conductance values both on a daily and average diurnal basis (figure $2 c$ ). Similarly, the difference between conductance values obtained using the two methods at low $D_{\mathrm{D}}$ decreased appreciably as compared with unconditionally averaged data (figure $2 d$ compared with figure $2 b$ ). Still, the range of values of conductance includes values too large to be considered reasonable. In addition to very large values of conductance, values approaching zero at low $\boldsymbol{D}$ may also be a result of small biases in measurement where estimated $\boldsymbol{E}_{\mathrm{C}}$ is relatively smaller than $\boldsymbol{D}$. 


\subsection{Effect of daily conditional averaging of conductances based on sample size}

Figure 3 illustrates that during days in which $D$ stays low, a very small sampling size may result for use in $G_{\mathrm{C} \text {,diu. }}$. Figure 4 demonstrates that when $\mathrm{n}<12$, the differ- ence between daily and averaged diurnal conductance calculations displays large variation. Thus we defined a secondary condition which operated on whole days, using the criteria of a minimum sample size of $n$ $=12$ (or $6 \mathrm{~h}$ at our sampling rate) for inclusion. The result of this second condition for acceptance is shown in figure $2 e, f$. The

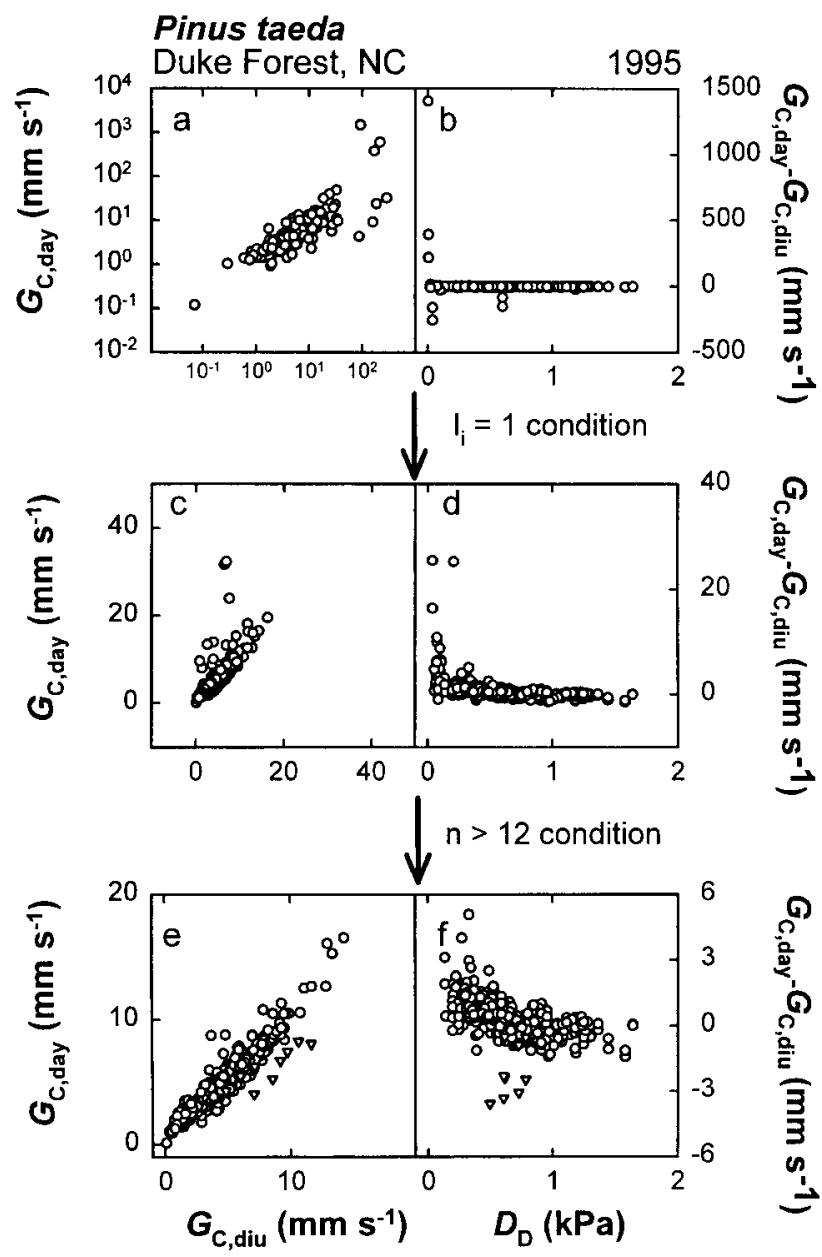

Figure 2. (a) Canopy conductances based on equation ( 1 ) averaged from mean daily conditions $\left(\boldsymbol{G}_{\mathrm{C}, \mathrm{day}}\right)$ versus those based on averaging diurnal values $\left(\boldsymbol{G}_{\mathrm{C} \text {,diu }}\right)$ when photosynthetically active radiation $(\mathrm{PAR})>0 \mu \mathrm{mol} \mathrm{m} \mathrm{m}^{-2} \mathrm{~s}^{-1}$. (b) The difference between $\boldsymbol{G}_{\mathrm{C} \text {,day }}$ and $\boldsymbol{G}_{\mathrm{C} \text {,diu }}$ versus standardized daily vapor pressure deficit $\left(\boldsymbol{D}_{\mathrm{D}}\right)$. (c) Same variables as in (a), but satisfying the condition $\mathrm{I}_{\mathrm{i}}=1$ (i.e. excluding values of $\boldsymbol{D}<0.1 \mathrm{kPa}$, see text for details); note the change in scale. (d) Same as variables in (b) with same condition. (e) Same variables as in (c) after satisfying the condition $\mathrm{n}>12$ (see text); note the change in scale. (f) Same variables as in (d) with same condition. 


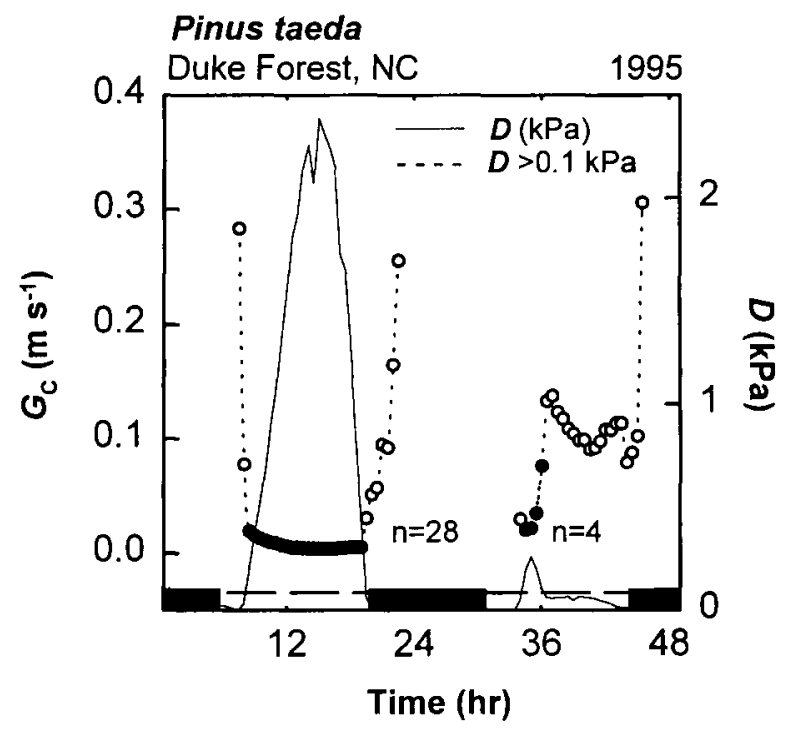

Figure 3. Two diurnal courses of conductance $\left(\boldsymbol{G}_{C}\right)$ and vapor pressure deficit $(\boldsymbol{D})$, illustrating the effect of the selected diurnal conditions for inclusion of data. Open symbols represent excluded data, closed symbols represent included data, and $\boldsymbol{D}$ is shown as a solid curve. The threshold $\boldsymbol{D}$ $=0.1 \mathrm{kPa}$ is shown as a dashed line. Conditions in which PAR $<0 \mu \mathrm{mol} \mathrm{m}^{-2} \mathrm{~s}^{-1}$ are shown as solid filled bars. The first day illustrates an accepted day after being subjected to the diurnal condition. The second day represents an excluded day since the number of accepted diurnal values was less than 12 .

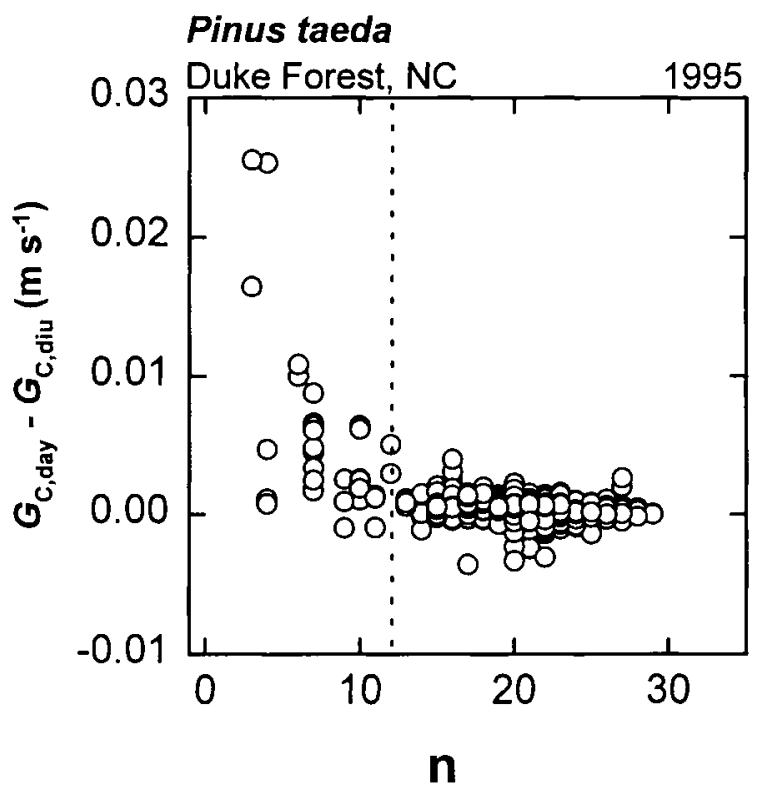

Figure 4. Difference between conductances based on mean daily conditions $\left(\boldsymbol{G}_{C \text { day }}\right)$ and those based on diurnal averaging $\left(\boldsymbol{G}_{\mathrm{C} . \mathrm{diu}}\right)$, as a function of the number of accepted diurnal samples in a day, $n$. The $n=12$ cutoff is shown as a dotted line. 
agreement between daily conductance and diurnally averaged conductance has been further increased compared to figure $2 c, d$. This range in values is comparable with typical diurnal values of conductance in pine forests from other studies (e.g. [9, 25]). Still, several points (designated with triangle symbols) appear to lie outside of the general cluster of points. The specific conditions of those days were investigated in detail and were found to result from rain events at night. The effects of nighttime recharge in general and recharge due to rain events were evaluated next.

\subsection{Effects of daytime versus nighttime flux on the difference between $G_{\mathrm{C} \text {,day }}$ and $G_{\mathrm{C} \text {,diu }}$}

The two conditional averaging schemes resulted in reasonable values of daily con- ductance. Although the slope of daily calculated conductance $\left(\boldsymbol{G}_{\mathrm{C} \text { day }}\right)$ to diurnal averaged conductance $\left(\boldsymbol{G}_{\mathrm{C} \text {,diu }}\right)$ was less than one (slope $=0.96, P=0.001$, intercept $=5.2 \mathrm{e}-4, P=0.02$ ), due to the intercept term $\boldsymbol{G}_{\mathrm{C}, \mathrm{day}}$ was generally greater than $\boldsymbol{G}_{\mathrm{C} \text {.diu, }}$ especially at low values. We interpret this to be caused by the inclusion of water taken up in recharge at night in a calculation of $\boldsymbol{G}_{\mathrm{C} \text {,day }}$ which is not represented in $\boldsymbol{G}_{\mathrm{C}, \text { diu }}$, thus leading to a relatively lower $G_{\mathrm{C} \text {.diu }}$. We also expected this to be a function of the absolute magnitude of daily transpiration, as the 'proportion' of recharge decreases (in the absence of rain) as daytime flux increases. Figure 5 shows that as night uptake becomes a significant fraction of total daily water uptake, $\boldsymbol{G}_{\mathrm{C}, \text { day }}$ increasingly exceeds $\boldsymbol{G}_{\mathrm{C} \text { diu }}$. When night uptake exceeded ca $50 \%$ of total uptake, $\boldsymbol{G}_{\mathrm{C}, \text { diu }}$ decreased to ca $30 \%$ of $\boldsymbol{G}_{\mathrm{C}, \text { day }}$. At very low values of night uptake/total

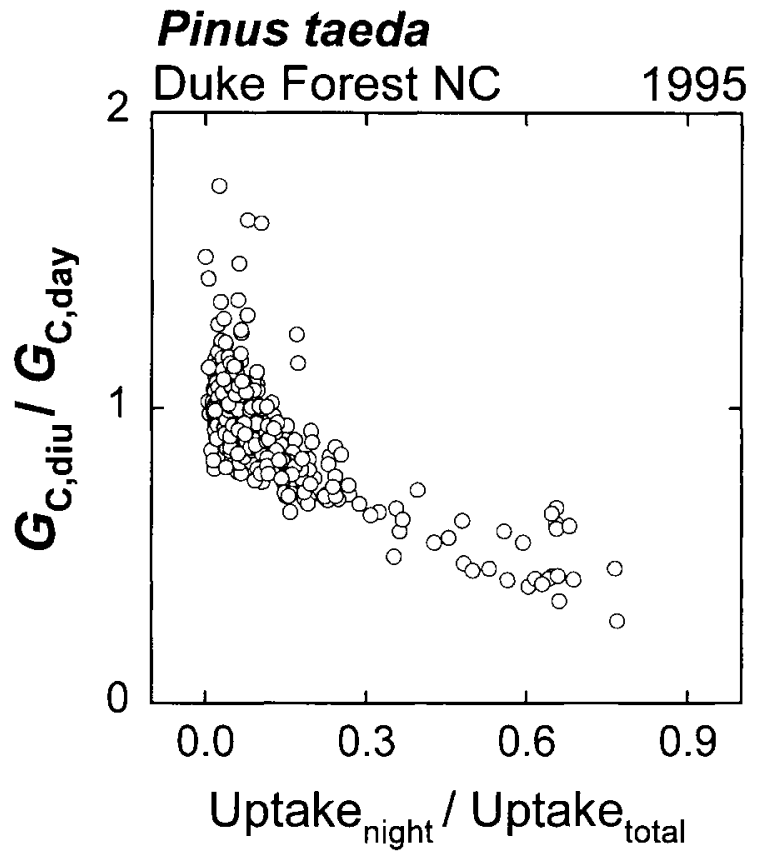

Figure 5. The ratio of conductances based on diurnal averaging $\left(G_{\mathrm{C}, \text { diu }}\right)$ to those based on mean daily conditions $\left(\boldsymbol{G}_{\mathrm{C}, \mathrm{day}}\right)$, as a function of nighttime uptake over total daily water flux. 
uptake, most ratios of $\boldsymbol{G}_{\mathrm{C}, \mathrm{diu}}: \boldsymbol{G}_{\mathrm{C} \text {,day }}$ clustered around unity, but several points were observed to reach higher values. Inspection of the original diurnal courses showed that these data came from days in which daytime values of $\boldsymbol{D}$ occurred which were only slightly greater than the threshold $0.1 \mathrm{kPa}$, but nevertheless led to relatively high calculated conductance values due to moderate flux rates. For instance, on 19 April 1995, three morning measurements of $\boldsymbol{D}$ (within light hours) that averaged only $0.35 \mathrm{kPa}$ led to diurnal values of conductance that averaged $15.9 \mathrm{~mm} \mathrm{~s}^{-1}$, while the rest of the daytime values $(n=19)$ averaged only $2.40 \mathrm{~mm} \mathrm{~s}^{-1}$. The effect of the three large values was to inflate $\boldsymbol{G}_{\mathrm{C} \text {,diu }}$ to $4.25 \mathrm{~mm} \mathrm{~s}^{-1}$ while $\boldsymbol{G}_{\mathrm{C} \text {,day }}$ was calculated as $2.85 \mathrm{~mm} \mathrm{~s}^{-1}$, close to the $2.40 \mathrm{~mm} \mathrm{~s}^{-1}$ of the other 19 points. This illustrates that diurnal averages of conductance may be highly sensitive to the choice of a threshold level of $\boldsymbol{D}$ used for diurnal conditional averaging. Thus, rather than finding a distinct threshold at which $\boldsymbol{D}$ creates biases in diurnal conductance averaging, a continuous bias may be introduced into diurnal conductance averages in which, as the conditional threshold is raised, a bias toward lower averaged diurnal conductance may be introduced. Additionally, changes in the conditional threshold would lead to changes in the average number of diurnal values accepted for averaging, potentially affecting the statistical representation of diurnal averages. Therefore a choice of a threshold $\boldsymbol{D}$ condition must balance 1) the effects of low point values of $\boldsymbol{D}$ and associated biases introduced as a result of both sensor error at low absolute rates, as well as 2) the effects of non-steady state behavior of stem sap flux in relation to canopy $D$, against 3 ) the legitimate inclusion of high conductance values occurring at low values of $\boldsymbol{D}$ and $\boldsymbol{E}_{\mathrm{C}}$ and 4 ) the need for enough data points within a daytime period to adequately characterize the daytime hours.
In addition to nighttime recharge due to the lag between transpiration and stem sap flow, fast re-hydration of xylem capacitance, which has been depleted by longerterm drying periods, occurs owing to rain events. Such rain events may introduce errors into $\boldsymbol{G}_{\mathrm{C} \text {,day }}$ or $\boldsymbol{G}_{\mathrm{C} \text {,diu }}$ calculations if recharge is mistaken for evaporativedemand driven sap flow. During daytime rain events, it is very difficult to separate sap flow driven by the environment from sap flow due to recharge. However, rain events which occur at night can lead to well-defined pulses of rain-induced recharge, permitting a quantification of their effects on calculations of $\boldsymbol{G}_{\mathrm{C} \text {,day }}$ versus $\boldsymbol{G}_{\mathrm{C} \text {.diu }}$, because $\boldsymbol{G}_{\mathrm{C} \text {,diu }}$ is not affected by nighttime rain recharge. Figure 6 presents data taken from 9-d selected from the long-term data set in which nighttime rain, and associated nighttime stem recharge, occurred. Although it cannot in general be excluded that nighttime raininduced recharge may contribute to water uptake during subsequent daylight hours, the data shown in figure 6 were taken from diurnal courses in which stable zero-flux baselines were observed after night rain recharges, yet before transpiration started. It is apparent that at lower integrated daytime stand transpiration, recharge of storage depleted over the long term can approach and even surpass the daytime value. While nighttime rains will introduce large errors into $G_{\mathrm{C} \text {, day }}$ estimates, daytime rain, especially during days of low $\boldsymbol{D}$ and $E_{\mathrm{C}}$, will introduce such errors into both estimates of conductance.

\subsection{Effect of tree size on nighttime-daytime flux}

If time taken for nighttime recharge were a function of tree volume, it would not be possible to use in a $\boldsymbol{G}_{\mathrm{C} \text {,day }}$ calculation an average, ground-based stand transpiration based on sap flow data from a range of tree sizes. Rather, each tree would 


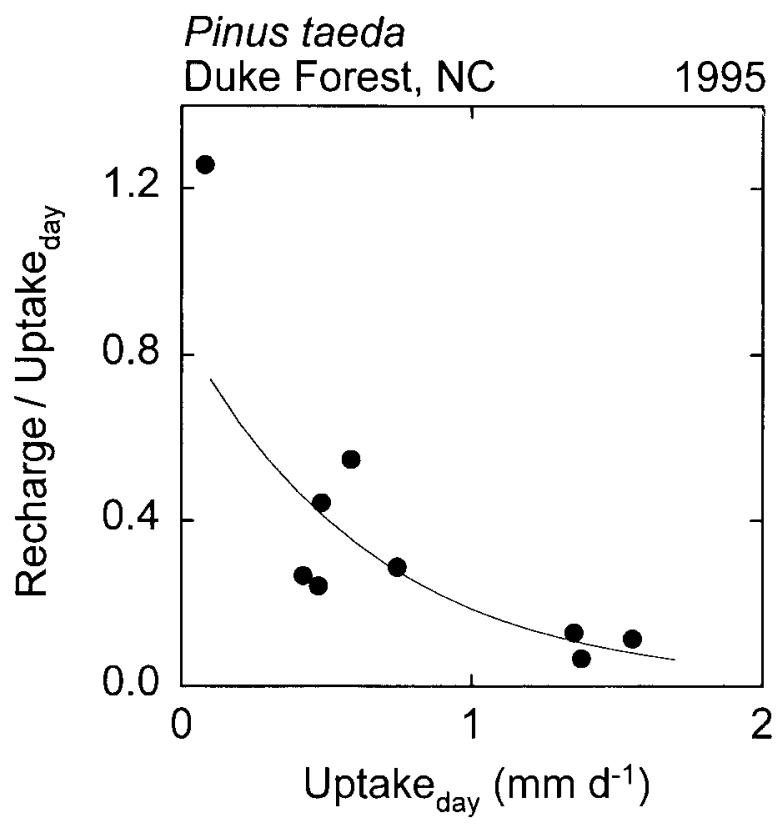

Figure 6. The effect of night rain events on recharge of long-term storage depletion as a proportion of daytime uptake, plotted against daytime uptake.

have to have its own conductance calculation, and the conductance computed from all measured trees would then be averaged. However, we did not find significant dependence of nighttime recharge on tree volume ( $P>0.1$; data not shown). Thus, we conclude that in the forest studied over the range of tree sizes monitored (dbh range $=110-201 \mathrm{~mm})$, conductance calculations may appropriately be performed on the average flux of a sample of trees exhibiting a range of volumes. Further studies on a larger range of tree sizes would be necessary in order to generalize this finding.

\subsection{Resulting seasonal course of daily conductance}

The result of the two-stage conditional averaging process employed in this study on the seasonal course of leaf-area weighted conductance, based on mean daily conditions, is shown in figure 7. Also shown are relevant environmental variables. In the $266 \mathrm{~d}$ record, $8 \mathrm{~d}$ were lost as a result of missing or bad data associated with sensor malfunction. Of the remaining $258 \mathrm{~d}$, the defined threshold conditions led to the exclusion from conductance calculations of an additional $23 \mathrm{~d}$.

\section{DISCUSSION}

Use of stem sap flow measuring techniques offers a tool for investigating the issue of temporally varying fluxes and surface resistance, but this technique is complicated by time variation both at the canopy level and throughout the xylem. Although the non-steady state behavior of water fluxes through the soil-plant-atmo- 


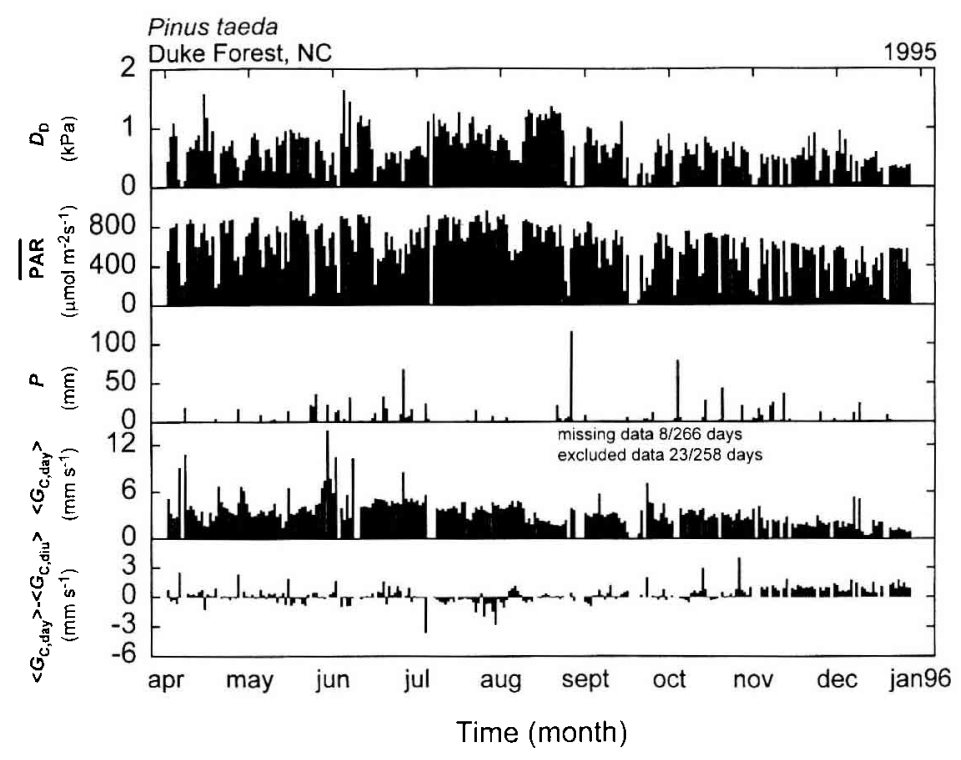

Figure 7. Seasonal courses of leaf-area based conductance based on mean daily conditions $\left(\boldsymbol{G}_{\mathrm{C} . \mathrm{day}}\right)$, and the difference between $\boldsymbol{G}_{\mathrm{C} . \mathrm{day}}$ and conductance based on diurnal averaging $\left(G_{\mathrm{C} . \mathrm{diu}}\right)$, following two-stage conditional averaging (see text). Also shown are daily standardized vapor pressure deficit, $\left(\boldsymbol{D}_{\mathrm{D}}\right)$, photosynthetically active radiation averaged over daylight hours $(\mathrm{PAR})$, and precipitation $(\boldsymbol{P})$.

sphere continuum has long been recognized [20,21], its effect on computations of canopy conductance when utilizing stem sap flux measurements has only recently begun to be investigated.

We have found that the simplest possible correction for non-steady state behavior of stem flow with respect to canopy flux - made from a lag analysis - was unable to satisfactorily identify a consistent time constant, thus, leading us to investigate further the utility and robustness of a daily conductance based on mean daily conditions. Our inability in this study to determine a consistent time lag which could be used to rectify the non-steady state relationship between stem flux and canopy transpiration is in contrast with earlier findings [32] in which a consistent time constant of about 45 min was estimated for stem flow responses to canopy flux. The discrepancy between results here and in the previous study may involve the length and timing of the present study (266 $\mathrm{d}$ through an entire growing season) versus that in the previous study $(50 \mathrm{~d}$ in the early part of a growing season). Although detailed soil moisture information was not available in the previous study, based on precipitation input and early growing season conditions, soil moisture was probably not limiting in that study. However, it has been shown that the time constant for nighttime recharge is an increasing function of soil moisture depletion in cases in which soil moisture is already relatively limiting [24, 31]. Thus, it is probable that in the present study, long-term variations of soil moisture, which included periods of significant moisture limitation, affected our ability to find a consistent time constant for stem response to canopy evaporative demand. 
The earlier finding that nighttime recharge increases as soil moisture becomes more depleted [31] presents another reason for concern in attempts to use averaged diurnal values of conductance in a daily conductance representation. If nighttime recharge increases as a function of soil drying, then larger proportions of flux at night relative to flux during the day (similar to that seen in figure 6), which would not be accounted for in the diurnal-averaging approach, would lead to an increasing underestimation of conductance (figure 5). This problem would be rectified when conductance calculations use mean daily conditions.

In this study, we have determined conditions in which a daily conductance based on mean daily meteorological conditions approaches that computed as the arithmetic mean of diurnal conductance values (figure 2 ). We found two primary conditions to be sufficiently high instantaneous values of $\boldsymbol{D}$ (figure 3 ), and a long enough period during the day in which such values occur (figure 4). Arithmetic means of diurnal surface conductance are often used as representations of daily conductance (e.g. [3]). However, it should be noted that the arithmetic mean of diurnal values may not be the best daily representation of conductance for use in predictions of total daily transpiration. The mean of diurnal values may be greatly affected by a few unreasonable values originating under conditions of low $\boldsymbol{E}_{\mathrm{C}}$ and $\boldsymbol{D}$ (figure 3 ; [2]). Furthermore, Monteith et al. [27] argued that diurnal conductance values should be weighted by some measure of available energy for evaporation, resulting in a daily weighted mean conductance. Variations of such weighting procedures have also been used by others $[8,38,40]$.

Thus, in order to provide more utility from our study for hydrological models, we compared both arithmetic mean conductance, $\boldsymbol{G}_{\mathrm{C}, \text { diu }}$, and conductance based on daily means, $\boldsymbol{G}_{\mathrm{C} \text {,day }}$ to a mean conductance weighted by above-canopy PAR (representing available energy). Figure 8 demonstrates a good relationship between both $\boldsymbol{G}_{\mathrm{C} \text {,diu }}$ and $\boldsymbol{G}_{\mathrm{C} \text {,day }}$ versus weighted daily conductance according to Monteith et al. [27], designated $\boldsymbol{G}_{\mathrm{C}, \text { Monteith }}$. Regressions for both $\boldsymbol{G}_{\mathrm{C} \text {,diu }}$ and $\boldsymbol{G}_{\mathrm{C} \text {,day }}$ versus $\boldsymbol{G}_{\mathrm{C} \text {,Monteith }}$ had slopes less than one $(0.90$ for $\boldsymbol{G}_{\mathrm{C}, \text { diu }}, P<0.0001 ; 0.88$ for $\boldsymbol{G}_{\mathrm{C} \text {,day, }}$ $P<0.0001)$, with slightly positive intercepts $\left(0.43 \mathrm{~mm} \mathrm{~s}^{-1}\right.$ for $\boldsymbol{G}_{\mathrm{C}, \mathrm{diu}}, P<0.0001$; $0.89 \mathrm{~mm} \mathrm{~s}^{-1}$ for $\left.\boldsymbol{G}_{\mathrm{C} \text {,day }}, P<0.0001\right)$, indicating that both $\boldsymbol{G}_{\mathrm{C} \text {,diu }}$ and $\boldsymbol{G}_{\mathrm{C} \text {,day }}$ were progressively lower than $\boldsymbol{G}_{\mathrm{C}, \text { Monteith }}$ as daily conductance increases. A positive intercept and positive slope less than unity arises because of the effects of diurnal covariance of $\boldsymbol{G}$ with PAR. When $\boldsymbol{G}$ and PAR covary strongly, $\boldsymbol{G}_{\mathrm{C}, \text { Monteith }}$ is weighed proportionally more relative to when $\boldsymbol{G}$ and PAR have little or negative covariance. This pivots the slope downwards and result in a positive intercept. Scatter in the relationship between $\boldsymbol{G}_{\mathrm{C} \text {,diu }}$ and $\boldsymbol{G}_{\mathrm{C}, \text { Monteith }}$ was found in cases where 1) extremely high diurnal values of apparent conductance accompanying daytime recharge of long-term storage depletion from rain were not adequately discounted by the weighted average procedure, while such points were eliminated from the diurnal average because $D<0.1 \mathrm{kPa}$, resulting in a relatively greater calculated $\boldsymbol{G}_{\mathrm{C} \text {.Monteith }}$ than $G_{\mathrm{C} \text {,diu }}$, and 2) late afternoon rain events associated with very low $D$ but substantial stem recharge led to high apparent conductance values which were discounted by the weighted averaging procedure since light was decreasing in the late afternoon, resulting in a relatively greater calculated $\boldsymbol{G}_{\mathrm{C}, \text { dit }}$ than $\boldsymbol{G}_{\mathrm{C}, \text { Monteith. }}$

For most applications involving daily surface conductance, it would be more desirable to have access to diurnal courses of conductance than daily means. However, when using stem sap flow techniques, such diurnal courses are affected 


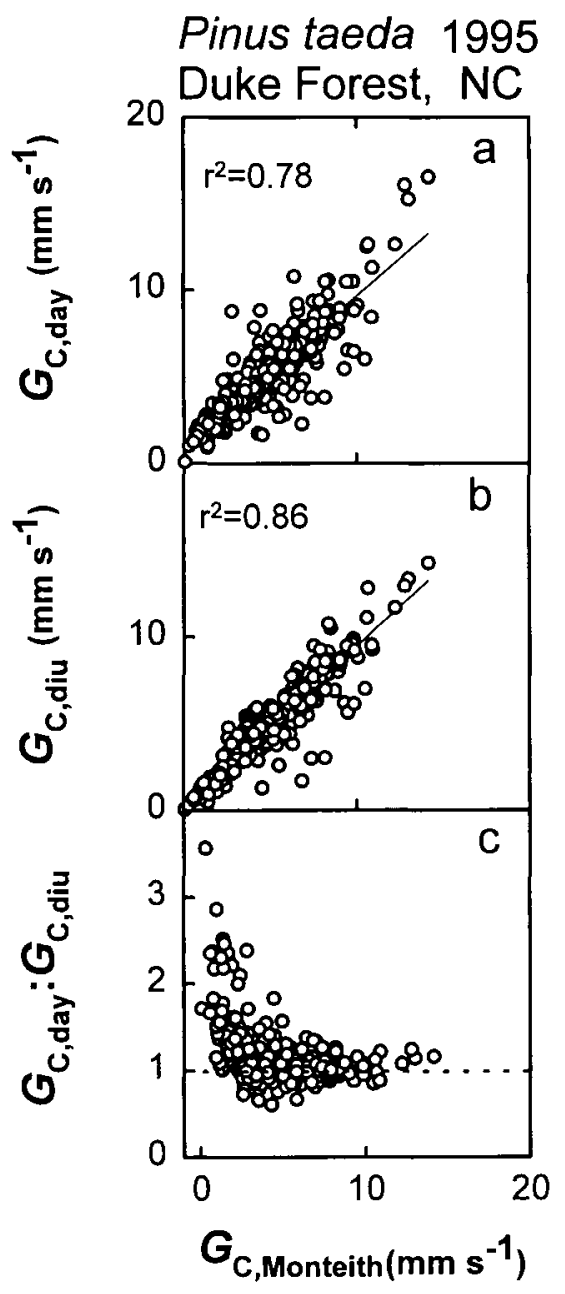

Figure 8. (a) Comparison between conductance based on mean daily conditions $\left(\boldsymbol{G}_{\mathrm{C} \text {.day }}\right)$, and conductance based on averaging of diurnal values weighted by photosynthetically active radiation $\left(\boldsymbol{G}_{\mathrm{C} . \text { Monteith }}\right.$; see text). (b) Comparison between conductance based on averaging of diurnal values $\left(\boldsymbol{G}_{\mathrm{C}, \text { diu }}\right.$ ) and $\boldsymbol{G}_{\mathrm{C}, \text { Monteith. }}$ (c) Ratio of daily to diurnal conductance versus $\boldsymbol{G}_{\mathrm{C} . \text { Monteith }}$.

by non-steady state conditions, causing a systematic underestimation in most conditions. Therefore, there is utility in using daily means. Daily means of conductance cannot be directly adjusted to include the effects of weighted averaging such as was carried out by Monteith et al. [27]. In applications for which a weighted daily mean suffices, a correction factor to $\boldsymbol{G}_{\mathrm{C} \text {,day }}$ may be approximated. For each day, the ratio of $\boldsymbol{G}_{\mathrm{C} \text {.Monteith }}$ to $\boldsymbol{G}_{\mathrm{C} \text {,diu }}$ can be calculated and multiplied by $\boldsymbol{G}_{\mathrm{C} \text {,day }}$. This incorporates the effect of diurnal weighting of conductance by available energy and more closely reflects the weighted averaging of Monteith et al. [27], but suffers less from 
the underestimation inherent in $\boldsymbol{G}_{\mathrm{C} \text {.diu }}$. We found that the correction factor ranging from null to two times $\boldsymbol{G}_{\mathrm{C} \text {,day }}$, was not dependent on $\boldsymbol{G}_{\mathrm{C} \text {,day }}$ or $\boldsymbol{D}$, and was not significantly different from unity for the entire data set $(1.006$; S.E. $=0.009)$.

\subsection{Seasonal course of $G_{C \text {,day }}$ in relation to leaf area dynamics and soil moisture conditions}

Seasonal patterns in $\boldsymbol{G}_{\mathrm{C} \text {,day }}$ are strongly affected by phenological and physical factors. In temperate forests, a general pattern of increased canopy conductance accompanies the increase in leaf area. This is very pronounced in deciduous forests, but is also clearly apparent in forests composed of non-deterministic evergreen species with highly dynamic leaf production and senescence. In $P$. taeda stands, $\boldsymbol{L}$ in September may be twice that in April [18]. We standardized $\boldsymbol{G}_{\mathrm{C} \text {,day }}$ by $\boldsymbol{L}$ so as to evaluate the general seasonal pattern in $\boldsymbol{G}_{\mathrm{C}, \text { day }}$ without the confounding dynamics in $\boldsymbol{L}$. This does not account for seasonal patterns in root growth which may have a profound effect on the ability of plants to follow the water table $[1,4,33]$, decouple $\boldsymbol{E}_{\mathrm{C}}$ from current precipitation, and maintain high $\boldsymbol{G}_{\mathrm{C} \text {,day }}$. Thus, species with deep rooting habits can take proportionally more water from deep horizons when growing season precipitation is low [33], and there may not be a relationship between short-term soil moisture depletion in the upper horizons and $G_{\mathrm{C} \text {,day }}$, but such trends may be found over the season [5].

Under conditions in which soil moisture reserves are available to plants, transpiration appears to follow potential evaporation [33]. In sites with deep soils occupied by deeply rooted species, soil moisture reserves become available through the process of forming new roots in deeper layers. In sites with shallow soils, or sites occupied with shallowly rooting species, soil moisture reserves are amply available only if they are replenished frequently by precipitation. In addition, for a given species, higher $\boldsymbol{L}$ results in higher $\boldsymbol{E}$ [14], exhausting soil moisture in a given layer faster. Thus, on a deep soil, a $P$. pinaster Ait. stand with low $\boldsymbol{L}$ showed a gradual decrease in canopy conductance to ca $50 \%$ in late summer of values in early spring, as the soil dried slowly [24]. Transpiration, however, was maintained high until mid-summer owing to increasing potential evaporation. Only in late summer did a combination of lower potential evaporation and canopy conductance finally reduce transpiration to $25 \%$ of the high, spring values, a reduction similar to that reported for a $P$. radiata $\mathrm{D}$. Don stand [42]. This seasonal pattern contrasts with responses of a $P$. pinaster stand on shallower soil and higher $\boldsymbol{L}$, in which transpiration declined rapidly between rain events, down to ca $15 \%$ over $8 \mathrm{~d}$ without precipitation [13]

Our stand shows intermediate sensitivity. Transpiration responded quickly to decreases in soil moisture availability by evapotranspiration, and increased with precipitation. Over $9 \mathrm{~d}$ without precipitation, transpiration decreased to $60 \%$ [27], a greater response than reported in Loustau et al. [24] but less than in Granier and Loustau [13]. Here, more frequent growing season precipitation than in the former study, and a deeper root system than in the latter study, could explain the lack of a clear seasonal pattern in $\boldsymbol{G}_{\mathrm{C} \text {,day }}$ within the growing season (April-October; figure 7). After October, low temperatures probably reduced $G_{\mathrm{C} \text {,day, }}$, as water uptake by $P$. taeda was shown to be very sensitive to soil temperature [22]. On a shorter timescale, $G_{\mathrm{C} \text {,day }}$ of $P$. taeda stand in this study showed faster response to rainless periods in August and September, when $\boldsymbol{L}$ was very high, than in May and June when $\boldsymbol{L}$ was much lower (figure 7). Soil moisture 
depletion proceeds at a high rate between rain events from July to September, often limiting $\boldsymbol{G}_{\mathrm{C} \text {,day }}[44]$. Using data presented in Oren et al. [29], we calculated $\boldsymbol{G}_{\mathrm{C}, \text { day }}$ over a 9-d drying period and related it to soil moisture depletion (figure 9). A 23$\mathrm{mm}$ decrease in soil moisture of the rooting zone (upper $0.35 \mathrm{~m}$ ) nearly halved $G_{\text {C,day }}$.

It is clear from viewing the difference between $G_{\mathrm{C} \text {,day }}$ and $G_{\mathrm{C} \text {,diu }}$ (figure 7 ) that this difference may be positive or negative, and is accentuated under rainy conditions. A positive difference indicates the influence of nighttime short- or long-term recharge accounted for in $G_{\mathrm{C} \text {,day }}$ but unaccounted for in $\boldsymbol{G}_{\mathrm{C} \text {,diu. }}$. A negative difference indicates inflated daytime values of conductance due to low $\boldsymbol{D}$ (frequently associated with daytime rain) that was slightly greater than the $0.1-\mathrm{kPa}$ threshold. Whether the difference in $\boldsymbol{G}_{\mathrm{C} \text {,day }}$ and $G_{\text {C,diu }}$ is positive or negative under conditions where rain occurs is largely dependent on the timing of the rain event diurnally, as daytime rain may lead to a relatively larger apparent $\boldsymbol{G}_{\mathrm{C} \text {,diu }}$ while nighttime rain may lead to a relatively larger $\boldsymbol{G}_{\mathrm{C}, \text { day }}$. In general, the $\boldsymbol{G}_{\mathrm{C} \text {,day }}$ values (figure 7 ) are similar to those reported for other conifers [13, 14, 19, 24]. However, occasionally, mostly associated with rain events that recharge stem storage after a rainless period (e.g. mid-June, figure 7), or with marginal conditions of low average $\boldsymbol{D}$ and $\boldsymbol{E}_{\mathrm{C}}$ (e.g. late December), unreasonable values of $\boldsymbol{G}_{\mathrm{C} \text {,day }}$ may result. Just as for calculating conductance using any

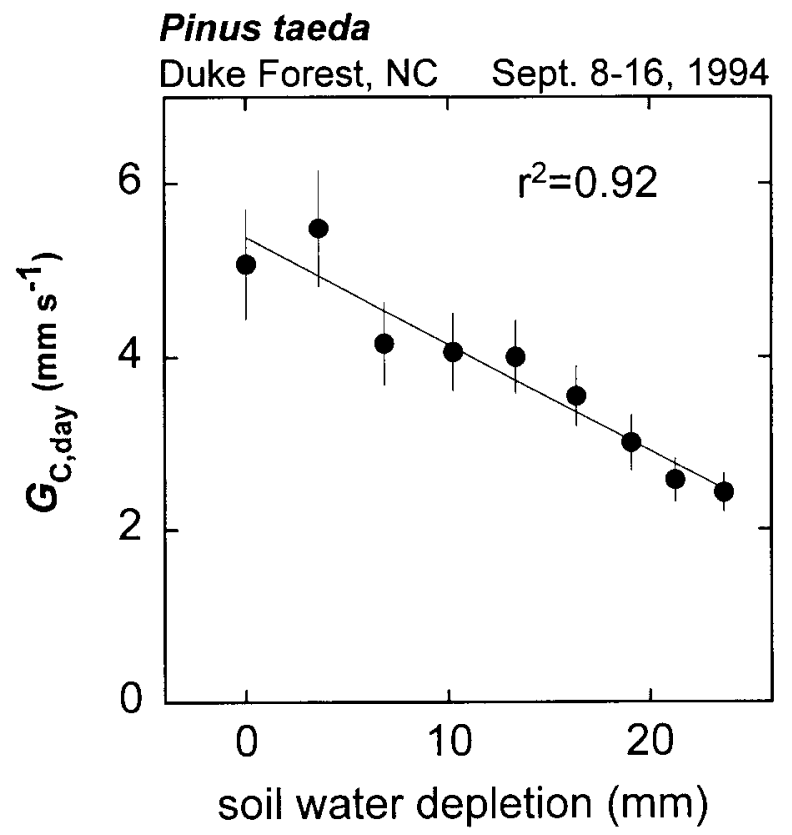

Figure 9. Decrease in conductance based on mean daily conditions ( $\boldsymbol{G}_{\mathrm{C} . \text { day }}$ ) with accumulated soil moisture depletion occurring over nine consecutive days in 1994. Standard error bars were calculated based on the variance associated only with daily stand water flux $\left(\boldsymbol{E}_{\mathrm{C}}\right)$. 
approach, it is necessary to evaluate the data for unusual conditions that may corrupt the calculations of $\boldsymbol{G}_{\mathrm{C} \text {,day. In com- }}$ parison to the $\boldsymbol{G}_{\mathrm{C} \text {,diu }}$ calculated from the arithmetic mean of the diurnal pattern, $\boldsymbol{G}_{\mathrm{C} \text {.day }}$ is affected less by short periods during the day in which $\boldsymbol{E}_{\mathrm{C}}$ and $\boldsymbol{D}$ are low, when errors in measurements are high. Furthermore, $\boldsymbol{G}_{\mathrm{C} \text {,day }}$ does not suffer from a systematic underestimation inherent in $\boldsymbol{G}_{\mathrm{C} \text {,duu }}$, which may be substantial in days of low $\boldsymbol{E}_{\mathrm{C}}$ and a high proportion of nighttime water uptake.

Acknowledgements: This study was funded by the US Department of Energy (DOE) through the National Institute for Global Environmental Change (NIGEC) Southeast Regional Center at the University of Alabama, Tuscaloosa (DOE Cooperative Agreement DEFC03-90ER61010).

\section{REFERENCES}

[1] Abrams M.D., Adaptation and responses to drought in Quercus species of North America, Tree Physiol. 7 (1990) 227-238.

[2] Berbigier P., Bonnefond J.M., Loustau D., Ferreira M.I., David J.S., Pereira J.S., Transpiration of a 64-year old maritime pine stand in Portugal: 2. Evapotranspiration and canopy stomatal conductance measured by an eddy covariance technique, Oecologia 107 (1996) 43-52.

[3] Bernhofer Ch., Blanford J.H., Siegwolf R. Wedler M., Applying single and two layer canopy models to derive conductances of a Scots pine plantation from micrometeorological measurements, Theor. Appl. Climatol. 53 (1996) 95-104.

[4] Bréda N., Granier A., Barataud F., Moyne C., Soil water dynamics in an oak stand. I. Soil moisture, water potentials and water uptake by roots, Plant and Soil 172 (1995) 17-27.

[5] Cienciala E., Lindroth A., Cermák J., Hällgren J.-E., Kucera J., The effects of water availability on transpiration, water potential and growth of Picea abies during a growing season, J. Hydrol. 155 (1994) 57-71.
[6] Couralt D., Lagouarde J.P., Aloui B., Evaporation for maritime catchments combining a meteorological model with vegetation information and airborne surface temperatures, Agric. For. Meteorol. 82 (1996) 93-117.

[7] Fennessey N.M., Vogel R.M., Regional models of potential evaporation and reference evapotranspiration for the northeast USA, J. Hydrol. 184 (1996) 337-354.

[8] Gash J.H.C., Stewart J.B., The average surface resistance of a pine forest derived from Bowen-ratio measurements, Boundary Layer Meteor. 8 (1975) 453-464.

[9] Gay L.W., Stewart J.B., Energy Balance studies in coniferous forests, Report No. 23, Instit. Hydrol. Natural Environ. Res. Council, Wallingford, Berkshire, 1974.

[10] Goff J.A., Gratch S., Low-pressure properties of water from - 160 to $212 \mathrm{~F}$, Trans. Am. Soc. Heating and Ventilation Engineers 52 (1946) 95-122.

[11] Granier A., Une nouvelle mäthode pour la mesure de flux de säve brute dans le tronc des arbes, Ann. Sci. For. 42 (1985) 193-200.

[12] Granier A., Evaluation of transpiration in a Douglas fir stand by means of sap flow measurements, Tree Physiol. 3 (1987) 309-320.

[13] Granier A., Loustau D., Measuring and modelling the transpiration of a maritime pine canopy from sap-flow data, Agric. For. Meteorol. 71 (1994) 61-81.

[14] Granier A., Biron P., Bréda N., Pontailler J.Y., Saugier B., Transpiration of trees and forest stands: short and long-term monitoring using sapflow methods, Global Change Biol. 2 (1996) 265-274.

[15] Hunt E.R., Running S.W., Federer C.A., Extrapolating plant water flow resistances and capacitances to regional scales, Agric. For. Meteorol. 54 (1991) 169-196.

[16] Jarvis P.G., The interpretation of the variations in leaf water potential and stomatal conductance found in canopies in the field, Phil. Trans. Roy. Soc. Lon. Ser. B 273 (1976) 593-610.

[17] Jarvis P.G., McNaughton K.G., Stomatal control of transpiration: scaling up from leaf to region, Adv. Ecol. Res. 15 (1986) 1-49.

[18] Kinerson R.S., Higginbotham K.O., Chapman R.C., The dynamics of foliage distribution within a forest canopy, J. App. Ecol. 11 (1974) 347-353.

[19] Köstner B., Biron P., Siegwolf R., Granier A., Estimating water vapor flux and canopy conductance of Scots pine at the tree level utilizing different xylem sap flow methods, Theor. Appl. Climatol. 53 (1996) 105-113.

[20] Kramer P.J., The relation between rate of transpiration and rate of absorption of water in plants, Am. J. Bot. 24 (1937) 10-15. 
[21] Kramer P.J., Root resistance as a cause of the absorption lag, Am. J. Bot. 25 (1938) 110-113.

[22] Kramer P.J., Species differences with respect to water absorption at low soil temperatures, Am. J. Bot. 29 (1942) 828-832.

[23] Kustas W.P., Stannard D.I., Allwine K.J., Variability in surface energy flux partitioning during Washita '92: Resulting effects on Penman-Monteith and Priestly-Taylor parameters, Agric. For. Meteorol. 82 (1996) 171-200.

[24] Loustau D., Berbigier P., Roumagnac P., Arruda-Pacheco C., David J.S., Ferreira M.I., Pereira J.S., Tavares R., Transpiration of a 64-year-old maritime pine stand in Portugal. 1. Seasonal course of water flux through maritime pine, Oecologia 107 (1996) 33-42.

[25] McNaughton K.G., Black T.A., A study of evapotranspiration from a Douglas fir forest using the energy balance approach, Water Resource Res. 9(6) (1973) 1579-1590.

[26] Monteith J.L., Unsworth M.H., Principles of Environmental Physics, Edward Arnold, London, 1990.

[27] Monteith J.L., Sceicz G., Waggoner P.E., The measurement and control of stomatal resistance in the field, J. App. Ecol. 2 (1965) 345-355.

[28] Oke T.R., Boundary Layer Climates, Routledge, London, New York, 1993.

[29] Oren R., Phillips N., Katul G., Ewers B., Pataki D.E., Scaling xylem sap flux and soil water balance, and calculating variance: $A$ method for partitioning water flux in forests, Ann. Sci. For. (1998).

[30] Pataki D.E., Oren R., Katul G., Sigmon J., Canopy conductance of Pinus taeda, Liquidambar styraciflua and Quercus phellos under varying atmospheric and soil moisture conditions, Tree Physiol. (1998).

[31] Phillips N., Oren R., Zimmermann R., Radial patterns of xylem sap flow in non-, diffuseand ring-porous tree species, Plant Cell Environ. 19 (1996) 983-990.

[32] Phillips N., Nagchaudhuri A., Oren R., Katul G.G., Time constant for water uptake in loblolly pine trees estimated from time series of stem sapflow and evaporative demand, Trees (1998).

[33] Rambal S., Water balance and pattern of root water uptake by a Quercus coccifera L. evergreen scrub, Oecologia 62 (1984) 18-25.

[34] Rochette P., Desjardins R.L., Dwyer L.M., Stewart D.W., Pattey E., Dube P.A., Estimation of maize (Zea mays L.) canopy conductance by scaling up leaf stomatal conductance, Agric. For. Meteorol. 54 (1991) $241-262$.
[35] Saugier B., Katerii N., Some plant factors controlling evapotranspiration, Agric. For. Meteorol. 54 ( 1991 ) 263-268.

[36] Schulze E.-D., Cermak J., Matyssek R., Penka M., Zimmermann R., Vasicek F., Gries W., Kucera J., Canopy transpiration and water fluxes in the xylem of the trunk of Larix and Picea trees - a comparison of xylem flow, porometer and cuvette measurements, Oecologia 66 (1985) 475-483.

[37] Shuttleworth W.J., The soil-vegetation-atmosphere interface, in: Raschke E., Jacob D. (Eds), Energy and Water Cycles in the Climate System, NATO ASI Series, Vol. 5, Springer-Verlag, Berlin, 1993, pp. 323-364.

[38] Szeicz G., Long I.F., Surface resistance of crop canopies, Water Resour. Res. 5 (1969) 622-633.

[39] Taconet O., Olioso A., Ben Mehrez M., Brisson N., Seasonal estimation of evaporation and stomatal conductance over a soybean field using surface IR temperatures, Agric. For. Meteorol. 73 (1995) 321-338.

[40] Tan C.S., Black T.A., Factors affecting the canopy resistance of a Douglas-Fir forest, Boundary Layer Meteor. 10 (1976) 475-488.

[41] Tattori S., Ikonen J.-P., Sucksdorff Y., A comparison of evapotranspiration above a barley field based on quality tested Bowen ratio data and Deardorff modeling, J. Hydrol. 170 (1995) 1-14.

[42] Teskey R.O., Sheriff D.W., Water use by Pinus radiata trees in a plantation, Tree Physiol. 16 (1996) 273-279.

[43] Thom A.S., Oliver H.R., On Penman's equation for estimating regional evapotranspiration, Quart. J. Roy. Meteor. Soc. 103 (1977) 345-357.

[44] Todd P.H., Use of a local mass balance method to determine the effects of soilwater conditions on canopy conductance and to estimate forest stand evapotranspiration in a natural forest and in growth chamber, MS Thesis, Duke University, Durham, NC, 1995.

[45] Wallace J.S., Calculating evaporation: resistance to factors, Agric. For. Meteorol. 73 (1995) 353-366.

[46] Whitehead D., Teskey R.O., Dynamic response of stomata to changing irradiance in loblolly pine (Pinus taeda L.), Tree Physiol. 15 (1995) 245-251

[47] Zhang L., Dawes W.R., Hatton T.J., Modelling hydrologic processes using a biophysically based model - application of WAVES to FIFE and HAPEX-MOBILHY, J. Hydrol. 185 (1996) 147-169. 